\title{
PELUANG DAN TANTANGAN INTERNASIONALISASI PEMIKIRAN MUHAMMADIYAH ${ }^{1}$
}

\section{- M. Amin Abdullah}

Guru Besar Filsafat di UIN Sunan Kalijaga Yogyakarta

Email: aminabdullah53@gmail.com

\section{Abstrak}

Studi ini mencoba membandingkan dan mengevaluasi dua gerakan Islam terbesar di dunia, yaitu Muhammadiyah dan Gulen Movement, khususnya dalam bidang internasionalisasi pemikiran Islam. Tampak bahwa, Gulen Movement memiliki banyak keunggulan dalam persoalan tersebut. Gerakan internasionalisasi yang dilakukan, telah merambah seluruh aspek kehidupan, khususnya di bidang pendidikan yang berbasis etos hizmet (voluntary services) yang menekankan pentingnya penguasaan sains mutakhir dan studi Islam. Hasilnya, para anggota Gulen Movement telah menyebar ke seluruh belahan dunia, yang diikuti oleh para anggota yang berasal dari negara-negara dan bangsa-bangsa yang tidak terbatas hanya pada warga negara Turki. Dalam konteks desaminasi kebajikan ini, Gulen Movement menarik untuk dipertimbangkan oleh organisasi-organisasi keagamaan di Indonesia, khususnya pula oleh Muhammadiyah yang berusia satu abad lebih. Dengan demikian, bila merujuk pada metode dan strategi Gulen Movement, peluang untuk memperkenalkan pemikiran Islam Indonesia yang unik, seperti Islam yang toleran, ramah dan moderat, akan membawa mimpi bersama umat Muslim Indonesia menjadi kenyataan.

Kata Kunci: Muhammadiyah, Internasionalisasi, Pemikiran Islam, Gulen Movement, Hizmet

1 Tulisan ini pernah dipresentasikan dalam acara "Tadarus Pemikiran Kaum Muda Muhammadiyah: Muhammadiyah dan Gerakan Sosial Baru” pada Jumat 14 Juli 2014 di Universitas Muhammadiyah Malang. Tulisan ini juga dipublikasikan di Jurnal Salam, Jurnal Studi Masyarakat Islam, Program Pascasarjana Universitas Muhammadiyah Malang, 2015, (dengan revisi seperlunya). 


\section{Pendahuluan}

Dalam tahun 2014, setidaknya, ada 2 tulisan peneliti dari luar negeri (outsiders) yang mengangkat Muhammadiyah dalam forum internasional lewat hasil penelitian yang diterbitkan dalam buku dan jurnal internasional. Pertama, adalah tulisan Martin van Bruinessen, - peneliti dari Belanda yang menguasai dengan baik bahasa Indonesia dan Turki, sering datang ke Indonesia, pernah mengajar di IAIN dan pada Juni 2014, mengajar di ICRS, UGM - yang berjudul, Secularism, Islamism and Muslim Intelectualism in Turkey and Indonesia: Some Comparative Observation². Kedua, peneliti dari Australia, Greg Barton, - menguasai bahasa Indonesia dengan baik, tapi tidak bahasa Turki - mempublikasikan tulisan yang berjudul The Gulen Movement, Muhammadiyah and Nahdlatul Ulama: Progressive Islamic Thought, Religious Philanthropy and Civil Society in Turkey and Indonesia ${ }^{3}$. Kedua tulisan ini sangat bagus untuk dikaji bersama dalam komunitas intelektual muda Muhammadiyah (Jaringan Intelektual Muda Muhammadiyah), terlebih lagi dalam konteks bagaimana menjawab peluang dan tantangan internasionalisasi pemikiran Islam Indonesia.

Kedua artikel tersebut, khususnya Martin, dalam bagian pembahasan tentang pemikiran Islam (Islamic Thought), membandingkan gerakan Muhammadiyah dan gerakan Gulen (Gulen Movement) dalam orientasi internasionalnya (international orientation), namun bukan internasionalisasi pemikiran Islam. Meski berbeda, namun penulis akan mencoba menjadikannya sebagai pintu untuk memasuki wilayah bahasan internasionalisasi pemikiran Islam Indonesia. Saya

2 Tulisan Martin van Bruinessen, kebetulan, didedikasikan kepada saya ketika saya melewati usia ke 60 tahun (28 Juli 1953). Di bawah judul artikelnya ditulis "Dedicated to Pak Amin Abdullah, who bridges the waters between Turkey and Indonesia”. Lebih lanjut Mirza Tirta Kusuma (Ed. dan Pengantar), Ketika Makkah Menjadi Seperti Las Vegas: Agama, Politik dan Ideologi (Jakarta: PT Gramedia Pustaka Utama, 2014), h. 130-157.

3 Greg Barton, "The Gulen Movement, "Muhammadiyah and Nahdlatul Ulama: Progressive Islamic Thought, Religious Philanthropy and Civil Society in Turkey and Indonesia," dalam Islam and Christian-Muslim Relations. Saya memperoleh artikel ini, ketika saya ke Istanbul dan ketemu mahasiswa Indonesia yang sedang mengambil program doktor di universitas Marmara, Istanbul, tanggal 24 Juni 2014. Dapat di akses di http://dx.doi.org/10.1080/09596410.2014.916124. Greg Barton pernah bertindak sebagai moderator dalam inter-faith dialog yang diselenggarakan oleh Sekolah Gulen dan masyarakat Turki di Melbourne di universitas Katolik Melbourne. Yang saya ingat, dia dengan fasih mengenalkan saya kepada para peserta seminar bahwa saya pernah memimpin Majelis Tarjih dan Pengembangan Pemikiran Islam, PP Muhammadiyah, tahun 1995-2000. Di Universitas Katolik Melbourne ini memang ada Gulen Chairs yang memfasilitasi para peneliti dan masyarakat umum untuk mengenal dan memahami Gulen movement. 
kutip terlebih dahulu tulisan Martin van Bruinessen yang terkait dengan international orientation:

“... Another striking difference between Muhammadiyah and the Gulen movement is in their international orientations. The Gulen movement is active in some 140 countries, and not just among Turks living there but among people of other ethnic and religious backgrounds (but the pride in Turkish identity, Turkish culture and Turkish history remains an important aspect of its activities). Muhammadiyah also has some activities abroad, but these are exclusively directed at fellow Indonesians. Muhammadiyah seems not to have the sense of mission, the belief it has something to offer to the world, that the Gulen movement displays. Prominent Muhammadiyah members may send their children to a Gulen school in Indonesia, because they are convinced of the quality of education offered. Young men and women of the Gulen movement are studying at various universities in Indonesia (as well as many other countries), not because they are convinced of the superiority of education at these institutions but - I believe - as a form of networking that will serve the movement's further expansion.".

Kutipan di awal tulisan ini hanya dimaksud untuk sedikit mengilustrasikan bagaimana peluang dan tantangan internasionalisasi pemikiran Islam Indonesia. Salah satunya adalah ukuran yang kira-kira dapat dipergunakan sebagai benchmarking antara Muhammadiyah dan Gulen Movement dari Turki, yang dalam waktu 20 tahun terakhir telah mendunia seperti sekarang ini. Tidak terlalu berlebihan jika dikatakan bahwa hampir tidak ada para peminat studi agama, studi keislaman, pegiat dialog antaragama, juga para pejabat yang berurusan dunia pendidikan dalam skala internasional yang tidak mengenal Gulen Movement. Apakah Muhammadiyah dalam 100 tahun lebih usianya memang tidak atau belum punya minat untuk go international, seperti go international-nya gerakan Gulen? Jika memang berniat atau berminat untuk go international, visi dan misi apa yang akan ditawarkan? Jika jawabannya positif "ya", apa langkah awal yang perlu ditempuh oleh pimpinan persyarikatan, aktivis, generasi muda Muhammadiyah, baik yang berlatar belakang pendidikan di dalam atau luar negeri? Baik yang berlatar belakang pendidikan dari Timur Tengah maupun Barat? Apakah hirarki dan birokrasi organisasi persyarikatan Muhammadiyah merestuinya? Apakah sistem pengkaderan yang dijalani selama ini kondusif untuk melangkah ke arah go international? Benchmarking ini perlu dan bahkan mendesak dilakukan mengingat perubahan sosial, budaya, ekonomi dan politik masyarakat Muslim di seluruh dunia dalam persentuhan dan

4 Martin van Bruinessen, Ibid., h. 151. 
perjumpaannya dengan bangsa-bangsa dan umat beragama yang lain pada era global abad ke 21 semakin tidak bisa dibendung.

\section{Tantangan Gerakan Sosio-Religius}

Akses ilmuwan dan intelektual Barat terhadap pemikiran Islam Indonesia lebih mudah dibandingkan ilmuwan, intelektual dan aktivis dari Timur Tengah. Belum lagi negara-negara berbahasa mandarin, seperti Tiongkok. Intelektual Barat lebih diuntungkan karena banyaknya tulisan dalam jurnal, penelitian, tesis dan disertasi di pusat-pusat studi di perguruan tinggi yang membuka kajian tentang Asia dan Indonesia. Belum lagi pusat-pusat religious dan theological studies di perguruan tinggi di Barat. Penelitian tentang Muhammadiyah dan Nahdlatul 'Ulama banyak dilakukan oleh para peneliti Barat dan diterbitkan dalam bahasa Inggris, sehingga akses untuk mengetahui pemikiran dan masyarakat Muslim Indonesia jauh lebih terbuka di Barat daripada di negara-negara Timur Tengah. Dalam diskusi penulis dengan Dr. Mariam Ait Ahmad, peneliti, penulis dan pemikir dari Maroko, dosen Universitas Ibn Tufayil, Rabat, Marokko menyatakan bahwa dia dan para koleganya di Maroko dan Timur Tengah yang lain pada umumnya ingin sekali memahami dengan baik buah pikiran Muslim Indonesia yang unik, moderat dan progresif. Ia menjadi ketua persahabatan IndonesiaMaroko di Rabat. Ia mengagumi buah pikiran Muslim Indonesia, tetapi dari sumber tangan kedua (secondary resources). Dengan tegas, ia menyatakan bahwa tidak satu pun intelektual Timur Tengah yang dapat mengakses buah pikiran intelektual Muslim Indonesia karena pemikiran Islam Indonesia tidak dapat diakses dalam bahasa Arab. Ia bercita-cita dan bermimpi mendirikan lembaga yang dapat menerjemahkan karya-karya dan pemikiran intelektual Muslim Indonesia, yang representatif ke dalam bahasa Arab, sehingga dapat diakses oleh para pembaca di Timur Tengah.

Pengalaman Indonesia sebagai negara mayoritas Muslim di dunia, yang menjalankan sistem demokrasi dalam negara-bangsa, bagaimana peran organisasi Muslim terbesar sebelum era kemerdekaan sampai sekarang, seperti Muhammadiyah (1912) dan Nahdlatul 'Ulama (1926), dalam merawat sistem negara-bangsa, hampir tidak bisa dikenali dengan baik karena langkanya buku atau literatur tentang pemikiran Islam Indonesia yang tertulis dalam bahasa Arab. Belum lagi yang terkait dengan hubungan agama (Islam) dengan budaya lokal yang sangat genuine, hubungan seni, budaya dan agama, sistem negara- 
bangsa yang berbentuk kepulauan, munculnya neo-sufism (hubungan yang proporsional antara syariah/hukum dan tasawuf), living Qur'an dan living Sunnah dalam masyarakat Indonesia, perkembangan Dirasat Islamiyyah/Islamic Studies di perguruan tinggi agama di Tanah Air, hubungan antara agama dan negara (bukan teokrasi, bukan sekuler), sistem negara Pancasila, hubungan antara penganut agama-agama di Nusantara (Muslim 87 \%; Non-Muslim 13\%), civil society, peran wanita, peran umat Islam dalam program Keluarga Berencana, implementasi konstitusi dalam bernegara dan berbangsa, belum lagi pemilihan presiden yang menggerakkan tidak kurang dari 180 juta pemilih yang dapat berjalan aman dan damai belum begitu banyak dikenal dengan baik di Timur Tengah.

Negara tidak mampu menangani hal ini secara lebih efektif. Negara belum maksimal, untuk tidak menyebutnya belum dapat memberi informasi yang lengkap tentang dinamika kesilaman, keindonesiaan dan kemodernan, serta kepostmodernan kepada bangsa-bangsa di dunia, baik oleh Kementerian Agama, Kementerian Pendidikan dan Kebudayaan, maupun Kementerian Luar Negeri. Hubungan yang bersifat sosial-kultural, people to people, culture to culture, tidak birokratis-formal, belum terumuskan dengan baik. Apakah perguruan tinggi Islam swasta seperti perguruan tinggi Muhammadiyah dan Nahdhatul 'Ulama atau lainnya dapat menawarkan dan mengulurkan jasanya untuk menangani halhal yang tidak dapat ditangani oleh pemerintah secara efektif?

Ini tantangan gerakan sosial baru di pentas global yang antara lain dihadapi oleh Muhammadiyah dan umat Islam yang lain di Indonesia. Adalah waktunya sekarang, Muhammadiyah dengan berbagai perguruan tinggi yang dimilikinya, lembaga-lembaga penelitian yang ada di dalamnya, jumlah dosen yang begitu banyak dapat berkontribusi mengisi kekosongan yang belum ditangani dan diisi oleh negara secara serius.

\section{Belajar dari Gulen Movement}

Fethullah Gulen (11 Nopember 1938) adalah seorang da'i biasa di Turki. Usianya sekarang sekitar 77 tahun. Sekarang tinggal di Pensylvania, Amerika Serikat, karena alasan kesehatan. Dulu, ia juga pegawai negeri biasa, yang tugasnya bertabligh di masjid-masjid di Turki. Sejak tahun 1970-an orientasi dakwahnya lebih menekankan pada pentingnya pendidikan. Tapi, bukan corak pendidikan yang biasa berjalan di Turki saat itu dan sekarang. Ia keliling kota- 
kota di Turki mendakwahkan pentingnya pendidikan untuk menaikkan kualitas umat Islam di Turki dan juga di manapun umat Islam berada.

Dalam himpitan hegemoni pemerintah yang sekuler-militaristik dan konservatisme umat Islam di Turki, Gulen berpikir out of the box. Ia serukan pentingnya pendidikan yang mementingkan sains modern. Pembangunan sekolah yang bermutu jauh lebih penting daripada pendirian tempat ibadah. Pembangunan tempat beribadah dirasa telah lebih dari cukup. Sistem pendidikan berasrama menjadi incaran cita-cita utamanya. Tema-tema agama, ilmu pengetahuan dan moral (faith, science and ethics) sangat kental dalam dakwah Gulen dan terus berkembang seiring dengan meningkatnya pengalaman dan luasnya pergaulan.

Pengaruh Badiuzzaman Said Nursi sangat kentara, khususnya dalam bidang politik. Ia menghindari keterlibatan langsung dengan politik praktis. "I take refuge in God from Satan and politics" (A'udzu billahi min al-syaitan wa al-siyasah), doanya Said Nursi yang diikuti oleh Fethullah Gulen. Penguasaan sains modern oleh anak didik menjadi obsesinya untuk menaikkan harkat dan martabat umat Islam di Turki dan juga di seantero dunia. Sains dan moralitas adalah bahasa global sekarang ini. Bukan agama - dalam artian hukum dan tradisi sosialkemasyarakatan, politik kekuasaan dan sistem ritual yang menjadi bahasa global sekarang. Karena sains modern, berikut kelengkapan laboratoriumnya hanya tersedia dalam bahasa Inggris, maka penguasaan bahasa asing, Inggris utamanya, adalah mutlak adanya. Corak bilingual schools menjadi pilihannya. Kesenian dan budaya lokal juga menjadi perhatiannya, termasuk musik, olah raga dan taritarian tradisional ${ }^{5}$.

Semua ini harus tersedia dalam sekolah yang bersistem boarding school. Ia juga mengajak dan menghimbau para pengusaha untuk peduli dan mendukung gerakan pendidikan baru yang diserukannya. Maka, kolaborasi dan himbauan kepada para pebisnis yang menjadi penopang gerakan pendidikannya, juga menjadi perhatiannya sejak awal.

Selain sains modern, agama tetap penting dalam kehidupan. Namun, moralitas dan etika agama jauh lebih ditekankan daripada aspek hukum dan ritualnya. Keteladanan (tamsil) lebih penting daripada sekedar menyampaikan

5 Banyak pejabat kementerian pendidikan dan kebudayaan, kepala-kepala sekolah SMA di beberapa daerah, pimpinan perguruan tinggi umum dan agama,serta beberapa tokoh masyarkat lintas agama dari Indonesia yang telah diajak berkunjung ke Turki untuk menyaksikan dari dekat sekolah-sekolah yang didirikan atas inspirasi Fethullah Gulen. 
(tabligh). Ritualnya mengikuti madzhab Hanafi. Shalat sunnah ba'diyyah-nya hampir-hampir tidak pernah mereka tinggalkan. Selain itu, hubungan sosial dan dialog antarbudaya dan agama menjadi perhatian utamanya. Maka, dialog antarbudaya dan agama menjadi salah satu prioritasnya.

Ketika negara-negara Asia Tengah (Kirgistan, Tajikistan, Uzbikestan, Turkminestan, Azerbaijan dan beberapa yang lainnya) merdeka, lepas dari kungkungan kekuasaan Uni Soviet pada 1990-an", orang-orang yang terinspirasi oleh pemikiran dan ide-ide pendidikan Gulen mulai tergerak dan terpanggil untuk masuk ke wilayah ini demi membantu menaikkan kualitas pendidikan. Tidak ada kesulitan, karena dari segi bahasa, mereka adalah satu rumpun. Inilah pengalaman internasional mereka yang pertama, yang kemudian dalam waktu singkat menyebar ke seluruh dunia.

Adalah di luar kupasan tulisan ini bagaimana Fethullah Gulen dan para sahabat generasi awal membentuk kader-kader gigih, ikhlas, berakhlak mulia, yang mau bersedia dan berkorban untuk dikirim ke seluruh negara dunia untuk dapat berkenalan, mencari partner, mencari wakif dan pengusaha setempat dan kemudian dilanjutkan dengan membangun dan mendirikan sekolah. Umumnya, sekolah yang mereka dirikan adalah setingkat SMP dan SMA. Ada juga beberapa SD dan PAUD. Sekarang sudah mulai merambah ke perguruan tinggi. Sekolahsekolah yang terinspirasi oleh Fethullah Gulen ini umumnya disebut oleh mereka dan para pengamat sebagai hizmet school.

Seingat penulis, sekitar tahun 1996, saya diundang Prof. Chamamah Suratno, yang saat itu menjabat sebagai dekan Fakultas Budaya di UGM, untuk berbicara dalam pertemuan di hotel Novotel Yogyakarta, yang bertujuan memperkenalkan kebudayaan Turki di lingkungan mahasiswa di Yogyakarta. Beberapa mahasiswa Turki, rupanya sudah mulai belajar bahasa Indonesia di UGM dan UI. Selain bertujuan menguasi bahasa Indonesia, mereka juga mencari kemungkinan partner pengusaha yang kiranya dapat bersama-sama mendirikan sekolah setingkat SMP dan SMA di Yogyakarta. Namun upaya itu belum berhasil karena belum menemukan partner dari Yogyakarta. Semarang lebih dahulu dari Yogya. Pebisnis dan pengusaha percetakan, Bapak H. Suwanto, menerima tawaran kerjasama tersebut dan bersedia merelakan tanahnya dan berdirilah sekolah Turki-Indonesia,

6 Thomas Michel, "The Thinking Behind the Gulen-Inspired School," dalam proseeding seminar The Significance of Education for the Future: The Gulen Model of Education, seminar yang diselenggarakan oleh Fethullah Gulen Chair, UIN Syarif Hidayatullah, Jakarta-Indonesia, 19-20 October 2010, h. 137. 
Sekolah Semesta, di Gunungpati, Semarang (Mei, 1999). Terdapat beberapa sekolah lain di Depok, Jakarta. Kemudian disusul sekolah Kharisma Bangsa di Jakarta. Kemudian, pasca tsunami di Banda Aceh, berdiri sekolah berasrama, asrama putera dan puteri, Fatih Bilingual School, dan di Yogyakarta, Sekolah Kesatuan Bangsa (2011), bertempat di gedung yang dulunya adalah bagian gedung dari universitas Wangsa Menggala di jalan Wates.

Kecepatan gerak internasionalisasi ini bukan hanya di Indonesia, melainkan juga di seluruh dunia. Martin van Bruinesseen menyebutkan bahwa sekarang sekolah-sekolah yang didirikan atas inspirasi ide pendidikan Fethullah Gulen ada di 140 negara. Selain ide genuine pendidikan sains yang diprioritaskan, juga dibekali etika beragama dan sosial yang kuat. Hizmet atau voluntary services menjadi etos bersama gerakan ini. Etos hizmet inilah yang ditanamkan dan meresap di setiap guru sains yang menyebar ke seluruh dunia dengan perangkat administrator sekolah, baik General Manager (GM) untuk mengurus segala kebutuhan sekolah dan asrama, karena hampir seluruh sekolah ini bersistem asrama (boarding school). Saya kutip tulisan Greg Barton:

“...The reforms of the early 1980s opened the door to the establishment of private schools and this provided new opportunities for the hizmet. In 1983, the movement opened two schools, one in Izmir and one in the historic Fatih district of Istanbul. These schools where to become models for the hundreds of hizmet schools that were opened in the following two decades. It is estimated that the total number of hizmet schools now exceeds 1200 world-wide, with hundreds of schools across Turkey, several hundred more in the Caucasus and in Central Asia, and the remainder in Europe, 7North America, Africa, Southeast Asia and Australia. "The precise number of the schools is difficult to ascertain as they represent the product of an organic movement in which there is no central coordinating hub but rather a network of local bodies intended to aid coopreation and mutual encouragement. Fethullah Gulen's relationship with the governing boards of the various schools is highly indirect and informal. The schools embody his vision of education and seek to represent his principles in concrete action, but they are locally run and managed."

Sekolah-sekolah ini tidak hanya berdiri di tempat-tempat yang aman dan normal seperti Indonesia dan negara-negara lain, tetapi juga di wilayah sulit, rawan konflik seperti Mindanao. Berikut kesaksian pastur dari Vatikan, yang pernah bertugas sebagai dosen di Sanata Dharma, Yogyakarta pada 1978-an dan

7 Greg Barton, Op. cit., h. 7 . Cetak miring dari saya. Banding dengan Martin van Bruinessen, Op. cit. h. $150-1$. 
juga di Fakultas Ilahiyyat, Universitas Ankara, Turki pada 1985-an, Thomas Michel:

"...My first encounter with one of these schools dates back to 1995. I was in Zamboanga, on the southern Philippine island of Mindanao, when I learned that there was a "Turkish" school several miles outside the city. As I approached the school, the first thing that caught my attention was the large sign at the entrance to the property, bearing the name 'The Philippine-Tukish School of Tolerance.' This name is a startling affirmation in Zamboanga, a city almost equally 50 percent Christian and 50 percent Muslim, located in the region where for more than twenty years various Moro separatist movements have been locked in an armed struggle against the military forces of the Philippine government." 8

\section{Internasionalisasi Gulen Movement}

Masyarakat dan para peneliti secara bersama mengajukan pertanyaan mengapa begitu cepat perkembangan sekolah-sekolah yang terinspirasi oleh visi pendidikan Fethullah Gulen dan menyebar ke seluruh dunia? Mencermati hasil kajian, pengamatan dan penelitian para peneliti dari berbagai negara memang banyak faktor yang bergerak secara simultan. Selain yang telah diungkap di atas, peran diplomasi budaya dan pendidikan memang sangat menonjol. Diplomasi budaya dan pendidikan yang diperankan oleh masyarakat sipil (civil society). Kunjungan budaya, muhibah studi banding (bahasa agamanya: silaturrahim) para tokoh dunia pendidikan, para peneliti, dosen, pimpinan perguruan tinggi, tokoh agama dari seluruh dunia ke Turki untuk melihat secara nyata praktik pendidikan ini juga sangat menentukan dan berkontribusi untuk membangun jembatan mutual understanding antara dunia Barat dengan Timur. Umumnya, mereka dibawa keliling ke beberapa sekolah sambil rekreasi ke sejumlah tempat wisata di Turki. Makan bersama di rumah keluarga sponsor PASIAD. Biaya perjalanan, akomodasi, semuanya ditanggung oleh PASIAD. Kunjungan ke negara dan masyarakat Turki ini semakin diyakini manfaat dan memiliki arti penting untuk menepis radikalisme dan terrorisme yang distigmatisasikan sejumlah pihak kepada umat Muslim di manapun mereka berada, khususnya pasca tragedi pengeboman World Trade Center (WTC) dan Phentagon, 11 September 2001.

8 Thomas Michel, "Fethullah Gulen as Educator," dalam M. Hakan Yavuz dan John L. Esposito (Eds.), Turkish Islam and The Secular State: The Gulen Movement (New York: Syracuse University Press, 2003), h. 70 . 
Mereka ingin menjawab tantangan ini. Tidak seburuk itu wajah budaya umat Islam di dunia. Masih banyak wajah ramah, santun, suka membantu, faith-based philanthrophy yang ada dalam masyarakat Muslim, khususnya di Turki. Penghilangan stereotyping dan stigmatisasi ini penting bagi kehormatan, keamanan dan hubungan bertetangga yang baik bagi para imigran Muslim dan para tetangganya di luar negeri.

Masih sejalan dengan diplomasi budaya dan pendidikan ini adalah dialog budaya dan agama. Fethullah Gulen pernah berkunjung ke Vatikan untuk melakukan pertemuan dengan Paus di Roma. Ia meyakini bahwa hanya dengan dialog antarbudaya dan agama dunia akan semakin kondusif untuk menjaga keamanan dan kesejahteraan warga global.

Kegiatan semakin intensif dilakukan setelah peristiwa 11 September 2001. Paling tidak, penulis dan sejumlah pimpinan perguruan tinggi dan tokoh organisasi sosial keagamaan di Indoensia pernah diundang, baik sebagai peserta (ke Moskow) maupun pembicara (di Tajikistan dan Melbourne) untuk menghadiri dialog antarbudaya dan agama9. Dalam kesimpulannya, Greg Barton memberi rangkuman terhadap pandangan Gulen tentang pentingnya dialog budaya dan agama sebagai berikut:

"a forward-looking, inclusive, tolerant and dialogical approach to Islam. This approach is most certainly post-Islamist in that it rejects, at a profound philosophical, theological and social level, the Islamist project of trying to change individuals and society topdown through sharia-minded legal reforms that would force people to become more 'pious'." 10

Selain itu semua, menurut hemat penulis, adalah kemampuan para individu penggerak gerakan ini untuk mendekati para penulis, peneliti dan dosen perguruan tinggi dari berbagai perguruan tinggi di luar Turki untuk melakukan penelitian tentang Gulen Movement di berbagai negara dan menerbitkannya dalam tulisan di buku maupun jurnal internasional. Para dosen, peneliti dan akademisi, baik di Turki maupun di sejumlah negara lain, secara suka rela atau atas permintaan untuk menulis dan meneliti tentang Gulen Movement seperti

9 M. Fethullah Gulen, Toward a Global Civilization of Love and Tolerance (New Jersey: The Light, Inc., 2004). Juga Ali Unal dan Alphonse Williams (Eds.), The Advocate of Dialogue: Fethullah Gulen (Fairfax. VA: Fountain, 2000).

10 Greg Barton, Op. cit. h. 3-4. 
Zeki Saritoprak, Elizabeth Ozdolga, Thomas Michel S.J., Lester R. Kurtz ${ }^{11}$, Hellen Rose Ebough ${ }^{12}$, M. Hakan Yavuz dan John L. Esposito ${ }^{13}$, Paul Weller dan Ihsan Yilmaz ${ }^{14}$, John O. Voll., Robert A. Hunt dan Yuksel A. Aslandogan ${ }^{15}$, Md. Maimul Ahsan Khan ${ }^{16}$, Greg Barton, bahkan juga Martin van Bruinessen menuliskannya dalam bentuk tulisan akademik dalam buku dan jurnal. Bahkan jurnal The Muslim World (2005) pernah mengangkat Special Issue tentang Islam in Contemporary Turkey: the Contribution of Fethullah Gulen, dengan editor tamu Zeki Saritoprak dari Department of Religious Studies, John Carroll University, Cleveland, Ohio, Amerika Serikat ${ }^{17}$.

Banyak hal belum tercakup dalam tulisan ini, tentang bagaimana membangun etos kesukarelaan, sehingga bisa menarik dan menggugah minat para pengusaha untuk mendukung pembangunan gedung sekolah yang representatif, laboratorium yang canggih, memberi beasiswa kepada para siswa dan mahasiswa, peran media baik elektronik (Radio, TV) maupun cetak, seperti harian Zaman (dalam bahasa Turki) yang beroplah 600.000 dan Today's Zaman (dalam bahasa Inggris) ${ }^{18}$. Namun, cukup kiranya telah dapat menggambarkan bagaimana Gulen Movement sebagai gerakan sosial-keagamaan (faith-based hizmet) baru yang mampu mengukir prestasi dalam pentas dunia global sekarang ini.

Dalam uraian ini, kita dapat membaca bahwa kehadiran gerakan Gulen di pentas dunia global, sedikit banyak mengobati kekecewaan dunia bahwa Islam

11 Tulisan semua nama penulis ini termuat di jurnal The Muslim World, Volume 95, Number 3, (July 2005).

12 Helen Rose Ebaugh, The Gulen Movement: A Sociological Analysis of a Civic Movement Rooted in Moderate Islam (New York: Springer, 2010).

13 M. Hakan Yavuz dan John L. Esposito (Eds.), Turkish Islam and the Secular State: The Gulen Movement (Syracuse, New York: Syracuse University Press, 2003).

14 Paul Weller dan Ihsan Yilmaz (Eds.), European Muslims, Civility and Public Life: Perspectives on and From the Gulen Movement (London dan New York: Continuum International Publishing Group, 2012).

15 Robert A. Hunt dan Yuksel A. Aslandogan (Eds.), Muslim Citizens of the Globalized World: Contributions of the Gulen Movement (Somerset NJ: The Light Inc. \& IID Press, 2006).

16 Md. Maimul Ahsan Khan, Introducing Fethullah Gulen to Bengal and Beyond (Dhaka: Raju Art Press, 2010).

17 The Muslim World, A Journal devoted to the study of Islam and Christian-Muslim relations, Special Issue, "Islam in Contemporary Turkey: the Contribution of Fethullah Gulen," Volume 95, Number 3 (July 2005).

18 Greg Barton, Ibid. h. 9. 
dan umatnya tidak semuanya berperilaku keras (hard liners), radikal dan teror, ketika menghadapi perubahan dunia yang maha dahsyat. Paling tidak, Gulen Movement dapat menjawab sekaligus menawarkan worldview keislaman baru yang lebih moderat, ramah, damai, sejuk dan menolak stigmatisasi terhadap umat Islam sebagai gerakan radikal, militan, bahkan teror pasca peristiwa WTC (2001) dan bom Bali (2002) dan berbagai tragedi atas nama agama yang lain di dunia.

\section{Internasionalisasi Pemikiran Islam Indonesia}

Jika Muhammadiyah dan umat Islam Indonesia yakin bahwa mereka memang mempunyai sesuatu yang dapat ditawarkan dan dibagikan kepada publik di pentas global (has something to offer to the world), maka sudah tiba saatnya sekarang Muhammadiyah, khususnya generasi mudanya merenung tentang sesuatu yang dapat ditawarkan dan yang hendak dikerjakan pada abad ke-21 ini, khususnya ketika Muhammadiyah telah melewati 100 tahun usianya (centennial anniversary). Peluangnya tetap ada, namun tantangannya juga jelas di hadapan bersama. Dalam hal ini, Indonesia sangat memiliki modal sosial, kultural dan ekonomi.

Masuknya Indonesia ke kelompok negara G20 adalah modal kuat bagi bangsa dan umat Islam Indonesia untuk berbicara dengan kepala tegak, percaya diri di hadapan bangsa-bangsa dunia. Belum lagi, jika benar prediksi para ekonom dunia bahwa pada 2030 - jangan-jangan lebih cepat dari itu - ekonomi Indonesia akan setingkat bahkan melewati kekuatan ekonomi negara-negara Eropa, seperti Jerman. Apa yang akan dilakukan Muhammadiyah, lebih-lebih kaum mudanya, menghadapi perubahan dunia dan Indonesia yang begitu cepat? Setidaknya, akan semakin banyak warga dunia, dari manapun mereka berasal, ingin tahu apa yang terjadi di Indonesia, termasuk pola pemikiran dan gerakan keagamaannya. Dengan mempertimbangkan pengalaman Gulen Movement, sebagai benchmarking, setidaknya, ada 3 (tiga) langkah yang perlu dipikirkan dan didesain untuk merealisasikannya:

Pertama, untuk memenuhi permintaan "pasar" intelektual Timur Tengah, paling tidak perguruan tinggi di bawah Muhammadiyah, juga berbagai perguruan tinggi Islam yang lain, perlu segera memelopori gerakan penerjemahan buku, artikel, khazanah sosial, budaya dan intelektual Muslim Indonesia yang berkualitas ke dalam bahasa Arab berstandar akademik tinggi, readable bagi kalangan 
intelektual dan akademisi pengguna bahasa Arab sebagai medium of teaching dan communication-nya. Pengguna bahasa Arab tidak hanya terbatas di wilayah Timur Tengah. Literatur berbahasa Arab akan menyebar ke daratan Eropa dan berbagai pusat studi agama dan keislaman di Eropa dan Amerika. Ketika membeli bukubuku berkualitas akademik tinggi yang berbahasa Arab terkadang malah lebih mudah dijumpai di Paris dan London, misalnya. Syukur juga dibarengi ke sejumlah bahasa lain, seperti Tiongkok, Jepang, Korea, dan beberapa bahasa di negara Eropa, selain berbahasa Inggris. Ibaratnya, Muhammadiyah melalui perguruan tinggi yang dimilikinya, seperti pada era Abbasiyah, khalifah alMa'mun mendirikan Baitul Hikmah untuk menerjemahkan karya dan manuskrip Yunani ke dalam bahasa Arab dan terus menjadi warisan (legacy) budaya dunia hingga sekarang. Dengan begitu, sharing experience dan transfer of knowledge tentang pengalaman unik dan genuine tentang perjumpaan keindonesiaan dan keislaman dapat diakses di Timur Tengah dan beberapa negara pada belahan dunia lain. Ini akan merupakan sumbangan yang tidak ternilai harganya bagi kebudayaan Islam dan peradaban dunia.

Kedua, "seperti yang dilakukan oleh Gulen Movement, setelah mempunyai jaringan sekolah di seluruh dunia(140 negara), mereka kemudian mendirikan perguruan tinggi, Fetih University di Istanbul, yang menggunakan bahasa Inggris sebagai medium of instruction-nya. Jauh lebih dahulu dari Fetih University Istanbul adalah International Islamic University of Malaysia (IIUM). Keduanya adalah contoh yang paling mudah dilihat dan dijadikan banchmarking tentang kemungkinan internasionalisasi pemikiran Islam Indonesia. Mungkin tidak harus langsung satu universitas diubah medium of instruction-nya dalam bahasa Inggris, seperti Fetih university atau IIUM, namun diawali dengan program khusus yang didesain untuk melayani minat mahasiswa internasional dari manapun datangnya. Asrama (dormitory) adalah salah satu syarat penting yang tidak dapat ditinggalkan dan berbagai universitas Muhammadiyah besar telah memilikinya. Memang perlu ada "sayap" persyarikatan dan itu adalah Perguruan Tinggi, yang mulai memikirkan kemungkinan merealisasikan mimpi besar ini. Ketiga, terlalu berat mengikuti jejak dan langkah Gulen Movement. Apalagi bukan itu tujuan utama ditulisnya makalah ini. Namun, cara berpikir out of the box itulah yang perlu diletadani. Mereka berani keluar dari zona nyaman dalam berpikir tentang pemikiran sosial, agama dan pendidikan. Perubahan cara berpikir dan mentalitas seperti itu yang dapat mengantarkan mereka dan 
jaringan internasionalnya seperti saat sekarang ini dalam upaya menginternasionalisasi visi dan misi kependidikannya ${ }^{19}$. Apa yang mereka lakukan dapat melampaui berlipat-kali dari apa yang dilakukan oleh negara dalam melakukan diplomasi budaya dan pendidikan.

Cara berpikir, mind set, dan mentalitas kaum muda intelektual Muslim pada khususnya dan pemuda Indonesia pada umumnya, terlebih lagi generasi kaum muda Muhammadiyah, sedikit banyak memang harus berubah. Penekanan mental dan cara berpikir bahwa manusia Indonesia dan umat Islam dimana pun berada adalah bagian tidak terpisahkan dari warga dunia (world citizenship) adalah tidak bisa tidak. Dengan mentalitas seperti itu, perubahan mental ini tidak mudah. Mereka pun pada saatnya akan mau dan rela berkorban dan bekerja di sekolah dan perguruan tinggi yang mereka dirikan di banyak negara.

\section{Penutup}

Langkah perubahan mental dalam masyarakat Muslim Indonesia merupakan keharusan. Sebagai teladan, masyarakat dan para intelektual Turki kelihatannya memang telah memiliki gairah revolusi mental seperti itu. Ini salah satu cara atau jalan lain untuk meraih cita-cita internasionalisasi pemikiran Islam Indonesia. Untuk keperluan diplomasi budaya dan pendidikan, mereka mau dan terpanggil untuk mempelajari bahasa lain selain bahasa Inggris dan bahasa-bahasa pemilik budaya ilmu pengetahuan yang lain. Mereka tidak merasa minder, memiliki selfconfidence untuk mempelajari bahasa asing non-Inggris dan Arab, demi untuk memperkenalkan dan menyampaikan visi dan misi pendidikan baru yang dianggapnya diperlukan oleh dunia di manapun mereka berada.

Kita bisa membayangkan betapa susahnya langkah yang ditempuh, khususnya di tahapan awal mencari partner di luar negeri, karena dengan bahasa yang masih terpatah-patah mereka berani menyampaikan visi dan misi pendidikan baru yang tidak ringan. Namun, karena dibantu dengan media sosial dan international networkings semuanya dapat berjalan seperti yang mereka alami sekarang ini. Islam berkemajuan yang menjadi tag line Muhammadiyah melintasi 100 tahun

19 Tidak hanya itu. The Presidency of Religious Affairs yang dimiliki negara juga punya Direktorat Urusan Luar Negeri, karena kebutuhan untuk melayani keperluan para imigran Turki di berbagai negara di dunia, khususnya Eropa. Mereka diminta mengirim imam dan khatib untuk mengisi kebutuhan masjid-masjid di negara-negara Eropa dan lainnya. Jika negara bekerja dalam ranah ini, Gulen movement bekerja dan berkarya dalam bidang garap yang lain, karena Gulen Movement adalah swasta sepenuhnya, tidak terkait dengan budget negara. 
usianya ditantang untuk menjawab ini semua. Apakah Muhammadiyah hanya akan terdeterminasi dan ditakdirkan untuk hanya khusus melayani lokalkeindonesiaan atau pada saatnya akan melangkah melewati pagar geografiteritorial, dan melintasi zona aman geografis yang selama ini menjadi habitusnya. Hanya generasi intelektual muda Muhammadiyah yang dapat memutuskan hal ini.

Generasi muda Muslim Turki merasa tidak nyaman untuk terus meninggali tempat dan zona aman di negaranya dan mereka berbondong-bondong sesuai kualifikasi profesionalitas yang dimilikinya untuk merantau, mencari tantangan baru di luar batas teritorial-kenegaraannya tanpa kehilangan identitas dan otentisitas keislaman dan keturkiannya. Pada saatnya, mereka juga kembali ke Tanah Air mereka, kembali menjadi warga negara biasa setelah mengabdi berkelana, merantau 5, 10, 15 tahun di luar negeri. Mereka, para guru sains ini, menjadi duta bangsa, duta-duta umat yang sesungguhnya.

Seperti usul Prof. Mitsuo Nakamura dalam diskusi di seminar memperingati 100 tahun berdirinya Muhammadiyah di Universitas Muhammadiyah Malang pada 2012 bahwa, Muhammadiyah suatu saat kelak memang perlu menyelenggarakan seminar, diskusi dan duduk bersama dengan praktisi dan pemikir gerakan Gulen untuk sharing experience dalam menghadapi tantangan dunia abad ke 21 dalam skala lokal, regional dan global sekaligus, khususnya terkait dengan pengalaman internasionalisasi pemikiran Islam. Usul yang penulis perkuat ketika itu, kemudian diulang lagi oleh Prof. Martin van Bruinessen dalam acara bedah buku di UIN Sunan Kalijaga, pada 18 Juni 2014.

\section{Bibliografi}

Aslandogan, Yuksel A. dan Robert A. Hunt (Eds.), Muslim Citizens of the Globalized World: Contributions of the Gulen Movement, Somerset NJ: The Light Inc. \& IID Press, 2006.

Barton, Greg, "The Gulen Movement, Muhammadiyah and Nahdlatul Ulama: Progressive Islamic Thought, Religious Philanthropy and Civil Society in Turkey and Indonesia”, Islam and Christian-Muslim Relations, http:// www.tandfonline.com/Loi/cicm20 diakses pada 24 Juni 2014.

Bruinessen, Martin van, "Secularism, Islamism and Muslim Intellectualism in Turkey and Indonesia: Some Comparative Observations," dalam Mirza Tirta Kusuma (ed.), Ketika Makkah Menjadi Seperti Las Vegas: Agama, Politik 
dan Ideologi, Jakarta: PT Gramedia Pustaka Utama, 2014.

Ebaugh, Helen Rose, The Gulen Movement: A Sociological Analysis of a Civic Movement Rooted in Moderate Islam, New York: Springer, 2010.

Esposito, John L. dan M. Hakan Yavuz, (Eds.). Turkish Islam and the Secular State:

The Gulen Movement, Syracuse, New York: Syracuse University Press, 2003. Gulen, M. Fethullah, Toward a Global Civilization: Love $\mathcal{E}$ Tolerance, New Jersey: Tughra Books, 2009.

Hunt, Robert A. and Yuksel A. Aslandogan (Eds.), Muslim Citizens of the Globalized World: Contributions of the Gulen Movement, New York: The Light Inc. \& IID Press, 2006.

International Fethullah Gulen Conference, Prosiding seminar The Significance of

Education for Our Future: The Gulen Model of Education, Jakarta, Fethullah Gulen Chair, 19-21 Oktober 2010.

Khan, Md. Maimul Ahsan. Introducing Fethullah Gulen to Bengal and Beyond, Dhaka: Raju Art Press, 2010.

Michel, Thomas. "Fethullah Gule as Educator," dalam M. Hakan Yavuz dan John L. Esposito (Eds.), Turkish Islam and The Secular State: The Gulen Movement, Syracuse, New York: Syracuse University Press, 2003.

Saritoprak, Zeki (ed.), "Islam in Contemporary Turkey: the Contributions of Fethullah Gulen,” The Muslim World, A Journal devoted to the study of Islam and Christian-Muslim Relations, Vol. 95, No. 3 (July 2005).

Williams, Alphonse dan Ali Unal (Eds.), The Advocate of Dialogue: Fethullah Gulen, Fairtax, VA: Fountain, 2000.

Yilmaz, Ihsan dan Paul Weller (Eds.), European Muslims, Civility and Public Life: Perspectives on and From the Gulen Movement, London dan New York: Continuum International Publishing Group, 2012. 